УДК 374:78(045)

DOI: 10.23951/1609-624X-2020-1-48-55

\title{
ШКОЛЬНЫЙ ТЕАТР КАК СРЕДСТВО РАЗВИТИЯ МУЗЫКАЛЬНО-ТВОРЧЕСКИХ СПОСОБНОСТЕЙ ДЕТЕЙ В УСЛОВИЯХ ДОПОЛНИТЕЛЬНОГО ОБРАЗОВАНИЯ*
}

\author{
С. В. Шишкина, Т. А. Шутова, Ю. В. Величко
}

Мордовский государственный педагогический институт имени М. Е. Евсевьева, Саранск

\begin{abstract}
Введение. Дополнительное образование обладает высоким потенциалом влияния на музыкально-творческое развитие детей. Одной из интегративных форм образовательной деятельности является школьный театр, в рамках которого актуализируются разносторонние творческие способности обучающихся: музыкальные (вокальные, инструментальные), танцевальные, пластические, актерские, словесно-драматические и др.

Цель - рассмотреть теоретико-методические основания развития музыкально-творческих способностей детей младшего школьного возраста в процессе театрализованной деятельности, осуществляемой в условиях дополнительного образования.

Материал и методы. Для выявления состояния проблемы музыкально-творческого развития детей в условиях дополнительного образования и ее решения использовался метод анализа психолого-педагогической и методической литературы, позволивший разработать творческие задания для участников музыкально-театрального кружка.

Результаты и обсуждение. В ходе исследования уточнены содержательные и структурные компоненты понятия «музыкально-творческие способности», включающие в себя общемузыкальные, специальные музыкальные (познавательные, исполнительские, творческие) и индивидуально-творческие способности детей (эмпатийность, артистизм, эмоциональность, образный характер мышления и др.). Подчеркивается, что музыкально-творческие способности - это комплекс личностных особенностей (мотивационной, эмоциональной, волевой, интеллектуальной и креативно-творческой сфер) и специальных способностей, необходимых для занятий искусством музыки. Методические рекомендации для педагогов описывают поэтапную организацию занятий в школьном театре (мотивационный, содержательный и процессуальный компоненты), наиболее эффективные методы музыкально-творческого развития обучающихся, исходя из возрастных и индивидуальных особенностей младших школьников, а также согласуясь с синтетической природой музыкально-театрального жанра и коллективной формой сотворчества педагога и учащихся.

Заключение. Развитие музыкально-творческих способностей у учащихся начальных классов средствами школьного театра зависит от организации учебного процесса, основанной на комплексном применении творческих заданий, направленных на формирование отдельно каждой структурной составляющей данных способностей, а также на их синтез. Эффективной формой проведения занятий в школьном театре в условиях дополнительного образования детей являются репетиции музыкально-театрализованных представлений, в ходе которых происходит не только музыкально-творческое, но и общекультурное развитие личности обучающихся, становление коллектива единомышленников.
\end{abstract}

Ключевые слова: школьный театр, музыкально-творческие способности, музыкально-театральные представления, дополнительное образование.

\section{Введение}

Развитие музыкально-творческих способностей детей - одна из актуальных задач в теории и практике современного дополнительного образования. Общеизвестно, что в любом виде человеческой деятельности ценится прежде всего творческая личность: человек, обладающий высоким творческим потенциалом в «интеллектуальных» видах деятельности, создает новые оригинальные продукты, а в массовом труде демонстрирует совершенствование процесса и средств, приводящее к его высокой эффективности. Данное высказывание подтверждается установками Концепции развития до- полнительного образования детей на 2014-2020 гг., согласно которым «дополнительное образование становится для взрослеющей личности смысловым социокультурным стержнем, ключевой характеристикой которого является познание через творчество, игру, труд и исследовательскую активность» $[1$, с. 4].

В рамках дополнительного образования все перечисленные виды познавательной деятельности сочетает в себе детский школьный театр как форма коллективной учебной работы, где объединяются музыка и драматургия, вокальное и инструментальное искусство, хореография и актерское твор-

\footnotetext{
* Исследование выполнено в рамках внутривузовского гранта Мордовского государственного педагогического института им. М. Е. Евсевьева по теме «Разработка учебно-методического обеспечения обязательных дисциплин и дисциплин по выбору вариативной части учебных планов магистратуры направления подготовки «Педагогическое образование» профиль «Дополнительное образование детей средствами искусства».
} 
чество. Музыкально-театрализованные представления, подготовленные детьми на репетициях школьного театра, являются весьма результативным средством развития музыкально-творческих способностей младших школьников.

В практике дополнительного образования накоплен богатый опыт по организации и руководству музыкально-театральными представлениями. Несложный сюжет, разыгрывание по ролям доставляют учащимся младших классов много удовольствия, при этом театральные постановки оказывают развивающее воздействие на личность ребенка, активизирующее музыкально-творческую деятельность (Н. А. Ветлугина, Н. А. Опарина, Л. Л. Пилипенко, И. В. Просандеева и др.).

Активное привлечение к участию в музыкально-театральных представлениях учащихся начальных классов основывается на возрастных творческих особенностях детей: именно в младшем школьном возрасте проявляется склонность к подражанию речи, мимике, пантомимике других людей; школьники быстро и прочно запоминают небольшие музыкальные и литературные тексты; дети различают и артистично передают речевые и музыкальные интонации; они обладают образным восприятием содержания произведений искусства. Однако, к сожалению, в современной школе уделяется недостаточно внимания музыкально-театральной деятельности и развитию музыкально-творческих способностей средствами школьного театра. Данное обстоятельство связано с рядом причин: это и неоднозначная трактовка в педагогической литературе понятия «музыкально-творческие способности» и структурных компонентов данных способностей в контексте театрализованной деятельности, и необходимость поиска и реализации новых методических подходов к решению проблемы развития данных способностей в сфере дополнительного образования учащихся, и нехватка специалистов, способных руководить школьным театром и обладающих, в свою очередь, компетенциями как в области музыкального образования, так и в сфере театральной педагогики. Противоречие между потребностью общества в музыкальнотворчески деятельных людях и реальным состоянием практики дополнительного музыкального образования, реализуемого в условиях общеобразовательной школы, обусловливает актуальность данного исследования.

\section{Материал и методы}

Материалом для исследования послужили музыкально-творческие способности младших школьников как показатели развития обучающихся на занятиях в школьном театре в рамках дополнительного образования. Методика изучения постав- ленной проблемы основывалась на анализе психолого-педагогической и методической литературы, позволившем разработать комплекс творческих заданий.

\section{Результаты и обсуждение}

Анализ проблемы развития музыкально-творческих способностей во многом предопределяется тем содержанием, которые мы вкладываем в это понятие, а также исходя из общепсихологического определения способностей человека.

Определение понятия «способности», с точки зрения ученых, связано с индивидуально-психологическими свойствами индивида, обеспечивающими успешность выполнения какого-либо вида деятельности и являющимися результатом выработанных ранее знаний, умений и навыков. Так, по мнению О. С. Виндекер, способности трактуются как «индивидуально-психологические особенности человека, выражающие его готовность к овладению определенными видами деятельности и к их успешному выполнению» [2, с. 59]. Значит, субъект, занимающийся музыкальным творчеством, должен обладать индивидуально-психологическими свойствами (или качествами), которые включают в себя мотивационную готовность к данному виду деятельности, а также знаниевый и практический компоненты сферы личности. Другими словами, музыкально-творческие способности представляют собой комплекс личностных особенностей (мотивационной, эмоциональной, волевой, интеллектуальной и креативно-творческой сфер) и специальных способностей, необходимых для занятий музыкальным искусством.

Для определения структуры данных способностей рассмотрим каждую из составляющих - музыкальную и творческую - поочередно.

Итак, среди работ, посвященных музыкальным способностям, фундаментальным трудом является книга Б. М. Теплова «Психология музыкальных способностей» [3]. Музыкальные способности, по мнению ученого, - это комплекс индивидуальнопсихологических свойств человека, обуславливающих восприятие, исполнение, сочинение музыки, обучаемость в области музыки [3]. Автор подчеркивает, что музыкальные способности ребенка проявляются в соответствующей деятельности, чаще всего в процессе сотрудничества с другими людьми. Значит, педагог правильным подходом, последовательностью методических приемов может повлиять на индивидуальное музыкальнотворческое развитие каждого ребенка опосредованно через коллектив. Данное утверждение важно для нашего исследования, так как занятия в школьном театре включают в основном групповую и коллективную формы творческой работы. 
Согласно Б. М. Теплову, классификация музыкальных способностей отражает два компонента: специальные (исполнительские, композиторские) и общие способности, необходимые для осуществления любой музыкальной деятельности. При этом специальные способности, или, другими словами, музыкальность, включают в себя все виды музыкального слуха, музыкально-слуховые представления, вокальные и инструментальные исполнительские способности, импровизационно-сочинительские способности, которые в деятельности сопровождаются эмоциональной реакцией - откликом, отзывчивостью на музыку, эмпатийными переживаниями художественного образа произведения искусства. Общие способности, по мнению ученого, проявляются в виде устойчивого внимания к музыкальной деятельности, произвольных и непроизвольных волевых усилий в ходе занятий музыкой, продуцирования ярких и активных зрительных и слуховых образов и т. д. [3, с. 24-62].

В современной психолого-педагогической литературе, продолжающей развивать идеи Б. М. Теплова, к музыкальным способностям относят также музыкальное восприятие, мышление, воображение (Д. К. Кирнарская, В. И. Петрушин, Г. С. Тарасов, Н. А. Терентьева Г. М. Цыпин и др.). Хотя нужно оговориться, что, по мнению других ученых, перечисленные качества являются не способностями, а музыкально-познавательными процессами, происходящими в психике обучающегося в ходе занятий музыкальной деятельностью.

Сущность музыкального восприятия заключается в активном отражении и переживании художественного образа произведения, при этом в процесс параллельно включается и деятельность по созданию субъективного образа музыки. Н. А. Терентьева выделяет следующие параметры музыкального восприятия школьников: эмоциональность (интенсивность чувственных переживаний, их соответствие художественному образу музыки); ассоциативность (способность к восприятию взаимосвязи между различными образами, отражение их многомерности в субъективных представлениях школьника); целостность (способность к обобщениям, синтезированному восприятию образов в эмоциональном и интеллектуальном их аспектах), дифференцированность (способность восприятия отдельных элементов) [4]. Отсюда к условиям, способствующим полноценному музыкальному восприятию, можно отнести наличие развитой чувственно-эмоциональной сферы у обучающегося, способность к эмпатии, сопереживанию музыкальным образам, ассоциативно-художественный опыт, интеллектуальные качества школьника.

Следующий компонент музыкальных способностей, важный для темы данного исследования, образное мышление младших школьников. В трак- товке педагогов и психологов в области музыкального образования - это сложный процесс интеллектуального преобразования чувственно воспринимаемой музыкально-эстетической информации в виде слуховых и зрительных образов. Отметим, что мышление зрительными образами, или, другими словами, «визуальное» мышление, хорошо развито у детей, потому что именно зрительная информация дает наибольший объем всего познаваемого учащимися объективного мира, в том числе и музыкально-культурного его компонента. Слуховые образы гармонично дополняют визуальную информацию и отражают собственно музыкальный аспект искусства. Образное мышление «опирается» на индивидуально-психологические особенности младшего школьника, поэтому образ отражает не только внешние, чувственно-воспринимаемые свойства объекта, но и «эмоциональноличностное отношение к ним» [5].

Говоря об образах, невозможно не затронуть такую специфическую человеческую способность, как воображение. Основой музыкального воображения являются ощущения (слуховые, зрительные, осязательные), которые, наравне с другими ощущениями, обладают инерцией последовательности. Музыкальное воображение позволяет продуцировать новые субъективные художественные образы и таким образом способствовать индивидуально-личностному и коллективно-общественному развитию обучающихся в сфере музыкального искусства.

Подчеркнем вслед за учеными, что все познавательные процессы (или способности) - восприятие, мышление, воображение - неразрывно взаимосвязаны и выделяются в науке условно, по доминирующему в данный момент виду музыкальной деятельности [6].

Итак, музыкальные способности, выделяемые в психолого-педагогических и специально-музыкальных исследованиях ученых, - это прежде всего «способность переживать музыку, способность создавать образы музыкальных произведений и выражать их как средствами музыкальной деятельности, так и средствами любой другой художественной деятельности (изобразительной, игровой, творческой)» [7, с. 32].

Следующий, творческий компонент в тандеме «музыкально-творческие способности» изучался педагогами, психологами, музыкантами достаточно активно. По мнению И. А. Неясовой и Ю. Н. Соколовой, «в творчестве ребенок выступает и как субъект деятельности, и как субъект познания, и как субъект переживания» [8, с. 49]. В исследованиях О. В. Милициной подчеркивается необходимость использования творческих видов деятельности в системе дополнительного образования, которые предоставляют «возможности реализовать 
интеллектуальный, творческий, ... личностный и другие потенциалы в ... практике» [9, с. 59].

В работе Н. В. Кондратьевой и В. П. Ковалева дается определение творческих способностей, которые трактуются как «синтез индивидуально-психофизиологических особенностей личности и новых качественных состояний (изменений в мышлении, восприятии, опыте жизнедеятельности, мотивационной сфере), возникающих в процессе новой для индивида деятельности (в процессе решения новых проблем, задач), что ведет к успешному ее выполнению или появлению субъективно/объективно нового продукта (идеи, предмета, художественного произведения и т. д.)» [10].

Основываясь на многочисленных исследованиях отечественных и зарубежных ученых, можно выделить отличительные черты творческих способностей: развитое воображение, эмоциональная чувствительность, нестандартный подход в решении поставленных задач, концентрация на главном, креативность мышления, способность памяти оперировать музыкальными образами, интеллектуальная активность, инициативность.

Синтез музыкальных и творческих компонентов дает структуру способностей, необходимых для воплощения театрализованных представлений в условиях школьного дополнительного образования: творческое восприятие музыки, музыкально-образное мышление, музыкальное воображение, способность к вокальному творчеству, инструментальному творчеству, пластическому воплощению музыкального образа (движения под музыку).

Анализ сущности и структуры понятия музыкально-творческих способностей, а также возрастных особенностей их развития у младших школьников позволил сделать вывод, что большое значение с этой точки зрения приобретают синтетические жанры искусства, где образы функционируют как целостные и воплощаются в комплексе восприятия, осмысления и творчества. Одним из таких синтетических жанров является театр, который позволяет комплексно подойти к процессу музыкально-творческого развития детей. Подтверждением этому служит опыт работ в области музыкально-театральной деятельности Ю. П. Азарова, Ю. Д. Белодубровской, Н. В. Боркиной, А. П. Ершова, А. М. Моисеевой, Е. Г. Савиной, Н. И. Сац, Н. С. Шерн и мн. др. Несмотря на разнообразие методических подходов к организации музыкально-театральной деятельности детей, авторов объединяет мысль о том, что успешность становления творчески развитой личности ребенка зависит от того, «как строится образовательно-воспитательный процесс, каковы содержательная, процессуальная и мотивационная стороны данного процесса» $[11$, с. 46].
Мотивационный компонент организации занятий в школьном театре связан с интересом и потребностью учащихся в музыкально-театральной деятельности, которые появляются при условии эмоциональной привлекательности содержания музыкально-сценического материала, а также его доступности в плане осмысления, запоминания и воплощения. Большую роль в формировании положительной мотивации у младших школьников играет стимулирование активности в групповой и коллективной музыкально-творческой деятельности, поощрение инициативности и свободы в выражении своих чувств, мыслей и пластических движений.

Содержательный компонент занятий включает подбор репертуара и определение педагогических методов его воплощения в музыкально-театральных представлениях. Как правило, музыкальносценические произведения должны быть ориентированы на художественно-эстетическое, нравственное, эмоциональное, интеллектуальное и творческое развитие младших школьников. Сюжетная линия, чувства и действия персонажей должны быть понятны и интересны всем участникам театрального коллектива. Зрительные, слуховые и пластические образы, воплощаемые в произведении, должны быть эмоционально выразительными, наглядными, яркими, динамичными. Как справедливо отмечает Л. Л. Пилипенко, «ребенок должен проникнуться эмоциональным состоянием героя, почувствовать, пережить то, что его волнует, удивляет, радует» [12].

Содержание учебно-воспитательных задач, реализуемых в процессе занятий в школьном театре, включает в себя: углубление знаний детей об окружающей музыкальной действительности; развитие музыкального восприятия, мышления, памяти, воображения учащихся; совершенствование артистизма при воплощении художественного образа героев сценического произведения; развитие вокальных, инструментальных и пластических импровизационных способностей; воспитание культуры музыкально-речевого общения в процессе репетиций и выступлений. По мнению Л. А. Безбородовой, предпосылками успешности реализации данных задач младшими школьниками в ходе занятий музыкально-театральным искусством являются «высокий уровень восприимчивости детей, чувственнообразный характер детского мышления, а также предрасположенность учащихся начальных классов к творчеству во всех его проявлениях» [13, с. 227].

Методические подходы к организации занятий школьного театра и постановке музыкально-театральных представлений, предлагаемые в педагогических исследованиях, позволяют выделить следующие этапы (процессуальный компонент): 
1) выбор сценария театрального представления, соответствующего возрасту учащихся, их индивидуальным и коллективным исполнительским возможностям;

2) демонстрация выбранного театрального представления детям: прослушивание записи, просмотр в детском театре и т. д.;

3) беседа по прослушанному музыкально-театральному представлению; выявление образов главных персонажей, анализ содержания в целом, выявление идеи и т. п.;

4) распределение ролей;

5) разучивание вокальных и инструментальных партий, хоровых номеров, танцевальных и пластических этюдов;

6) сведение по порядку сцен с постепенной усложненностью образа персонажа;

7) сводная репетиция, в которой акцент делается на восприятие представления как единого целого;

8) подготовка и оформление сцены; участники представляют самостоятельно выполненные костюмы, декорации, атрибуты к театральному представлению;

9) генеральная репетиция;

10) выступление;

11) анализ выступления совместно педагога с учащимися, оценка проделанной работы, информация о новых планах, поощрение.

На занятиях в школьном театре можно предложить следующие задания для развития музыкально-творческих способностей:

\section{Задание 1}

Цель задания: побуждать детей самостоятельно находить выразительные движения при создании образа под музыку, совершенствовать умение детей пластически двигаться в ритме и настроении музыкального произведения, синтезировать зрительные, слуховые и пластические образы.

Музыкальный материал: А. Джойс. Осенний сон.

Содержание задания: педагог предлагает детям представить осенний парк, деревья с облетающими листьями и, превратившись в листик, при помощи пластических движений покружиться под порывами ветра и плавно опуститься на землю.

\section{Задание 2}

Цель задания: развитие навыков вокальной импровизации, музыкального слуха и воображения.

Содержание задания: музыкальный диалог педагога и учащихся, в котором педагог исполняет вопросительные предложения песенки-загадки, а дети по очереди вокально импровизируют ответы.

Музыкальный материал: Муз. А. Пахмутовой, сл. Ю. Черных «Кто пасется на лугу?»

\section{Задание 3}

Цель задания: развитие способности к вокальной импровизации и эмоциональной отзывчивости на музыку у младших школьников, артистизма.

Содержание задания: педагог предлагает ребятам нарисовать сказочную страну, а затем пением «оживить» героев сказки: придумать свои варианты мелодий, которые поют герои сказки, когда им весело или они чего-то страшатся, когда шалят или побеждают недобрых героев.

\section{Задание 4}

Цель задания: развитие способности к инструментальной импровизации, развитие воображения.

Содержание задания: педагог раздает младшим школьникам шумовые музыкальные инструменты - маракасы, треугольник, бубен, барабан; ребята должны встроить свою импровизацию на инструменте в звучание музыкального произведения.

Музыкальный материал: С. Прокофьев «Дождь и радуга», П. И. Чайковский «Марш деревянных солдатиков» из цикла «Детский альбом».

Данные задания можно использовать для подготовки детей к участию в музыкально-театральных представлениях, одновременно развивая музыкально-творческие способности.

\section{Заключение}

В настоящее время в сфере музыкального образования активно разрабатывается система дополнительного образования, связанная с задачами раскрытия творческого потенциала обучающегося, реализации гуманно-личностного подхода к образовательному процессу и формирования в нем новой культуры отношений между педагогом и детьми.

Реализация потребности детей в творчестве, развитие музыкально-творческих способностей достаточно эффективно осуществляются в процессе вовлечения учащихся в театральную деятельность. Театральное искусство, отмечает А. Н. Матвеева, близко к сущности ребенка, его общению [14]. В этой связи школьный театр содержит в себе такие возможности раскрытия и реализации личности, какие не могут быть раскрыты и реализованы в традиционной учебной деятельности. По словам А. Л. Михайловой, театр помогает ребенку попробовать себя в роли «создателя возможных художественных форм», принадлежащих разным видам искусства [15].

Методические подходы к организации занятий школьного театра и постановке музыкально-театральных представлений, а также творческие задания, представленные выше, были реализованы педагогами МОУ «Центр образования «Тавла» средняя общеобразовательная школа № 17» г. о. Саранск в кружковой деятельности. На регио- 
нальном этапе окружного фестиваля «Театральное Приволжье» коллективом школьного театра была представлена музыкальная версия сказки «Про Емелю дурака». Выступление юных артистов продемонстрировало не только общемузыкальное развитие личности младших школьников, но и развитие специальных музыкально-творческих способностей, например, музыкально-познавательных компонентов (восприятие, мышление, воображение) и импровизационных способностей (вокальные, инструментальные, двигательно-пластические). Дети, занимавшиеся в театральном кружке в прошлом году, с удовольствием посещают его занятия и в настоящее время. Многие из участников одновременно с кружковыми занятиями записались в музыкальную школу и танцевальную студию, что доказывает положительную мотивационную направленность и заинтересованность детей в музыкально-творческой деятельности.

Авторы считают, что эффективность теоретических положений, представленных в статье, под- тверждается практическими результатами работы с младшими школьниками в ходе организации дополнительного образования средствами театрального искусства. Таким образом, опыт детской театральной деятельности неоднократно убеждает в том, что участие школьников в театрально-творческом процессе создает наилучшие условия для развития личности, и именно в творчестве рождается и закрепляется любовь к музыкальному искусству и театру на всю жизнь - обилие форм и методов учебной и воспитательной работы;

- теснейшая связь труда и обучения;

- использование игротехник как фактора формирования познавательного интереса у обучающихся.

Представленные в работе составляющие моделей образовательной среды калужских исследователей способствуют оптимизации включения юношества в разнообразные виды деятельности, а значит, его дальнейшему успешному развитию через привитие умений и навыков добывать знания.

\section{Список литературы}

1. Распоряжение Правительства Российской Федерации от 04.09.2014 г. № 1726-р «Об утверждении Концепции развития дополнительного образования детей» // Официальный сайт Правительства России. URL: static.government.ruımedia/files/ipA1NW42XOA.pdf (дата обращения: 26.11.2019).

2. Виндекер О. С. Диффреренциальная психология (прикладные аспекты): учебно-метод. пособие. Екатеринбург: Изд-во Урал. ун-та, 2016. $76 \mathrm{c.}$

3. Теплов Б. М. Психология музыкальных способностей. М.; Л.: Изд-во АПН РСФСР, 1947. 335 с.

4. Терентьева Н. А. Художественно-творческое развитие младших школьников на уроках музыки в процессе целостного восприятия различных видов искусства. М.: Прометей, 1990. 184 с.

5. Гогоберидзе А. Г., Дергунская В. А. Теория и методика музыкального воспитания детей дошкольного возраста: учебное пособие для студ. высш. учебн. заведений. М.: Академия, 2005. 230 с.

6. Выготский Л. С. Воображение и творчество в детском возрасте: психологические очерки. 3-е изд. М.: Просвещение, 1991. 90 с.

7. Половинко Э. Р. Педагогическое обеспечение развития музыкальных способностей младших школьников средствами дидактической игры: дис. ... канд. пед. наук. Уфа, 2014. 242 с.

8. Неясова И. А., Соколова Ю. Н. Особенности формирования опыта творческой деятельности у младших школьников в условиях дополнительного образования // Гуманитарные науки и образование. 2017. № 4 (32). С. 45-51.

9. Милицина О. В. Этнокультурная направленность подготовки бакалавра педагогического образования (профиль «Музыка») к реализации дополнительного образования // Гуманитарные науки и образование. 2017. № 2 (30). С. 57-61.

10. Кондратьева Н. В., Ковалев В. П. Структура творческих способностей младших школьников // Современные проблемы науки и образования. 2015. № 5. URL: http://science-education.ru/ru/article/view?id=21736 (дата обращения: 08.11.2019).

11. Шишкина С. В. Использование техники монотипии в процессе музыкально-творческого развития учащихся // Актуальные проблемы высшего музыкального образования. 2012. № 5. С. 45-47.

12. Пилипенко Л. Л. Развитие эмоциональной отзывчивости младших школьников в условиях детского музыкального театра: дис. ... канд. пед. наук. Екатеринбург, 1999. 120 с.

13. Безбородова Л. А. Теория и методика музыкального образования: учебное пособие. 2-е изд., стер. М.: Флинта, 2014. 240 с.

14. Матвеева А. Н. Театр как вид искусства и его воспитательное значение в школе // Библиотека. 2004. № 8. С. 14-16.

15. Михайлова А. Л. Ребенок в мире театра: методич. пособие по воспитанию зрительской культуры. М.: Просвещение, 2001. 143 с.

Шишкина Светлана Владимировна, доцент, Мордовский государственный педагогический институт имени М. Е. Евсевьева (ул. Студенческая, 11а, Саранск, Республика Мордовия, Россия, 430007). E-mail: sv430903@yandex.ru

Шутова Татьяна Александровна, старший преподаватель, Мордовский государственный педагогический институт имени М. Е. Евсевьева (ул. Студенческая, 11a, Саранск, Республика Мордовия, Россия, 430007).

E-mail: tatiana230373@rambler.ru 
Величко Юлия Викторовна, доцент, Мордовский государственный педагогический институт имени М. Е. Евсевьева (ул. Студенческая, 11a, Саранск, Республика Мордовия, Россия, 430007). E-mail: july.veli4ko@yandex.ru

\title{
SCHOOL THEATER AS A MEANS OF DEVELOPMENT OF MUSICAL AND CREATIVE ABILITIES OF CHILDREN IN THE CONDITIONS OF ADDITIONAL EDUCATION
}

\author{
S. V. Shishkina, T. A. Shutova, Yu. V. Velichko
}

Mordovian State Pedagogical Institute named after M. E. Evsevyev, Saransk, Russian Federation

Introduction. Additional education has a high potential to influence the musical and creative development of children. One of the integrative forms of educational activity is the school theater, in which the versatile creative abilities of students are updated: musical (vocal, instrumental), dance, plastic, acting, verbal and dramatic, etc. The purpose of the article is to consider the theoretical and methodological grounds for the development of musical and creative abilities of children of primary school age in the process of theatrical activities carried out in the conditions of additional education.

Material and methods. To identify the status of the problem of musical-creative development of children in terms of further education and its solution used the method of analysis of psycho-pedagogical and methodological literature and empirical methods, allowing to develop and test creative task for the participants of the musical-theatre group.

Results and discussion. The study clarifies the content and structural components of the concept of "musical and creative abilities", including General musical, special musical (cognitive, performing, creative) and individual creative abilities of children (empathy, artistry, emotionality, imaginative nature of thinking, etc.). Methodical recommendations for teachers describe the phased organization of classes in the school theater (motivational, content and procedural components), the most effective methods of musical and creative development of students, based on the age and individual characteristics of younger students, as well as consistent with the synthetic nature of the musical theater genre and the collective form of co-creation of the teacher and students.

Conclusion. The development of musical and creative abilities of primary school students by means of school theater depends on the organization of the educational process, based on the complex application of creative tasks aimed at the formation of each structural component of these abilities separately, as well as their synthesis. An effective form of instruction in school theater from the point of view of additional education of children is rehearsal of musical and theatrical performances, in which not only the musical, creative and cultural development of the personality of students takes place, the formation of a group of like-minded people.

Keywords: school theater, musical and creative abilities, musical and theatrical performances, additional education.

\section{References}

1. Rasporyazheniye Pravitel'stva Rossiyskoy Federatsii ot 04.09 .2014 g. No. 1726-r "Ob utverzhdenii Kontseptsii razvitiya dopolnitel'nogo obrazovaniya detey" [The order of the Government of the Russian Federation of 04.09.2014 No. 1726-r "On Approving the Concept for the Development of Further Education for Children"]. Ofitsial' nyy sayt Pravitel'stva Rossii - Official website of the Government of Russia (in Russian). URL: static.government.ruımedia/files/ipA1NW42XOA.pdf. (accessed 26 November 2019).

2. Vindeker O. S. Differentsial'naya psikhologiya (prikladnyye aspekty): ucheb.-metod. posobiye [Differential psychology: (applied aspects): teaching aid]. Ekaterinburg, Ural University Publ., 2016. 76 p. (in Russian).

3. Teplov B. M. Psikhologiya muzykal'nykh sposobnostey [Psychology of musical abilities]. Moscow-Leningrad, APS RSFSR Publ., 1947. 335 p. (in Russian).

4. Terent'eva N. A. Khudozhestvenno-tvorcheskoye razvitiye mladshikh shkol'nikov na urokakh muzyki v protsesse tselostnogo vospriyatiya razlichnykh vidov iskusstva [Artistic and creative development of younger students at music lessons in the process of holistic perception of different types of art]. Moscow, Prometey Publ., 1990. 184 p. (in Russian).

5. Gogoberidze A. G., Dergunskaya V. A. Teoriya i metodika muzykal'nogo vospitaniya detey doshkol'nogo vozrasta: ucheb. posobiye dlya stud. vyssh. uchebn. zavedeniy [Theory and methodology of musical education of preschool children: a textbook for students of higher educational institutions]. Moscow, Akademiya Publ., 2005. 230 p. (in Russian).

6. Vygotskiy L. S. Voobrazheniye i tvorchestvo $v$ detskom vozraste: psihkhologicheskiye ocherki [Imagination and creativity in childhood: psychological essays]. Moscow, Prosveshcheniye Publ., 1991. 90 p. (in Russian).

7. Polovinko E. R. Pedagogicheskoye obespecheniye razvitiya muzykal'nykh sposobnostey mladshikh shkol'nikov sredstvami didakticheskoy igry. Dis. cand. ped. nauk [Pedagogical support of development of musical abilities of younger pupils by means of didactic game. Diss. cand. of ped. sci.]. Ufa, 2014. 242 p. (in Russian). 
8. Neyasova I. A., Sokolova Yu. N. Osobennosti formirovaniya opyta tvorcheskoy deyatel'nosti u mladshikh shkol'nikov v usloviyakh dopolnitel'nogo obrazovaniya [Features of formation of creative activity experience of junior schoolchildren in the conditions of additional education]. Gumanitarnyye nauki i obrazovaniye - The Humanities and Education, 2017, no. 4 (32), pp. 45-51 (in Russian).

9. Militsina O. V. Etnokul'turnaya napravlennost' podgotovki bakalavra pedagogicheskogo obrazovaniya (profil' «Muzyka») k realizatsii dopolnitel'nogo obrazovaniya [Ethnocultural orientation in training Bachelors of pedagogical education (profile «Music») to implement additional education]. Gumanitarnyye nauki i obrazovaniye - The Humanities and Education, 2017, no. 2 (30), pp. 57-61 (in Russian).

10. Kondrat'yeva N. V., Kovalev V. P. Struktura tvorcheskikh sposobnostey mladshikh shkol'nikov [Structure of creative abilities of younger schoolchildren]. Sovremennyye problem nauki i obrazovaniya - Modern problems of science and education, 2015, no. 5 (in Russian). URL: http:/l science-education.ru/ru/article/view?id=21736 (accessed 8 November 2019).

11. Shishkina S. V. Ispol'zovaniye tekhniki monotipii v protsesse muzykal'no-tvorcheskogo razvitiya uchashchikhsya [The use of monotype technique in the process of musical and creative development of students]. Aktual'nyye problemy vysshego muzykal'nogo obrazovaniya, 2012, no. 5, pp. 45-47 (in Russian).

12. Pilipenko L. L. Razvitiye emotsional'noy otzyvchivosti mladshikh shkol'nikov v usloviyakh detskogo muzykal'nogo teatra. Dis. cand. ped. nauk. [Development of emotional responsiveness of younger schoolchildren in the conditions of children's musical theater. Diss. cand. of ped. sci.]. Ekaterinburg, 1999. 120 p. (in Russian).

13. Bezborodova L. A. Teoriya i metodika muzykal'nogo obrazovaniya: ucheb. posobiye [Theory and methodology of music education. A textbook]. Moscow, Flinta Publ., 2014. 240 p. (in Russian).

14. Matveyeva A. N. Teatr kak vid iskusstva i ego vospitatel'noye znacheniye v shkole [Theatre as an art form and its educational value in school]. Biblioteka, 2004, no. 8, pp. 14-16 (in Russian).

15. Michaylova A. L. Rebenok v mire teatra: metodich. posobiye po vospitaniyu zritel'skoy cul'tury [A child in the world of theater: methodical manual on education of spectator culture]. Moscow, Prosveshcheniye Publ., 2001. 143 p. (in Russian).

Shishkina S. V., Mordovian State Pedagogical Institute named after M. E. Evsevyev (ul. Studencheskaya, 11a, Saransk, The Republic of Mordovia, Russian Federation, 430007). E-mail: sv430903@yandex.ru

Shutova T. A., Mordovian State Pedagogical Institute named after M. E. Evsevyev (ul. Studencheskaya, 11a, Saransk, The Republic of Mordovia, Russian Federation, 430007). E-mail: tatiana230373@rambler.ru

Velichko Yu. V., Mordovian State Pedagogical Institute named after M. E. Evsevyev (ul. Studencheskaya, 11a, Saransk, The Republic of Mordovia, Russian Federation, 430007). E-mail: july.veli4ko@yandex.ru 